\title{
Tensile strength of galvanized iron glass fiber sandwich panel.
}

\author{
Gurustal Somnath Swamy ${ }^{1}$, Srikanth Rangdal ${ }^{2}$, Mohammed Ghufran Uddin ${ }^{3}$, \\ Mahantesh Katagi ${ }^{4}$. \\ ${ }^{\text {I}}$ Department of Mechanical Engineering, Aurora Scientific Technological and Research Academy, JNTUH, \\ Telangana, India) \\ ${ }^{2}$ (Department of Mechanical Engineering, Nishitha College of Engineering and Technology, Peeran Cheru, \\ Himayat Sagar Road, Hyderabad, Telangana, India) \\ ${ }^{3}$ (Department of Mechanical Engineering, Shadan College of Engineering and Technology, On Srisailam \\ Highway, Near International Airport, Hyderabad, Telangana, India) \\ ${ }^{4}$ (Department of Mechanical Engineering, Aurora Scientific Technological and Research Academy, JNTUH, \\ Telangana, India)
}

\begin{abstract}
The composite materials are replacing the traditional materials, because of its superior properties such as high tensile strength, low thermal expansion, high strength to weight ratio. The developments of new materials are on the anvil and are growing day by day. The recent need to develop a new range of materials has resulted in the development of high performance lightweight composites with excellent properties. Mixing of metals with Glass-Fiber Reinforced Polymers (GFRPs) is finding increased applications. Metal-composite systems consist of alternating layers of metal and fiber-reinforced polymer composites which are bonded by an adhesive. In this study, a galvanized iron glass fiber reinforced plastic sandwich panel composite is developed and their tensile strength is evaluated. Experimental results were in good agreement with predictions from simple models. On an overall basis, the sandwich panel exhibited better tensile strength performance than the monolithic galvanized iron.
\end{abstract}

\section{Introduction}

The term composite can be defined as a material composed of two or more different materials, with the properties of the resultant material being superior to the properties of the individual materials being superior to the properties of individual material that make up the composite.

Glass Fiber Reinforced Polymers (GFRPs) is a fiber reinforced polymer made of a plastic matrix reinforced by fine fibers of glass. Fiber glass is a lightweight, strong, and robust material used in different industries due to their excellent properties. Although strength properties are somewhat lower than carbon fiber and it is less stiff, the material is typically far less brittle, and the raw materials are much less expensive. Its bulk strength and weight properties are very favorable when compared to metals, and it can be easily formed using molding processes several researches have been taken place in this direction.

Sandwich structured composites are a special class of composite materials which have become very popular due to high specific strength and bending stiffness. Low density of these materials makes them especially suitable for use in aeronautical, space and marine applications Sandwich composites primarily have two components namely, skin and core. If an adhesive is used to bind skins with the core, the adhesive layer can also be considered as an additional component in the structure. The thickness of the adhesive layer is generally neglected because it is much smaller than the thickness of skins or the core. The properties of sandwich composites depend upon properties of the core and skins, their relative thickness and the bonding characteristics between them. Other advantages offered by sandwich construction are elimination of welding, superior insulating qualities and design versatility. Even if the concept of sandwich construction is not very new, it has primarily been adopted for non-strength part of structures in the last decade. This is because there are a variety of problem areas to be overcome when the sandwich construction is applied to design of dynamically loaded structures. To enhance the attractiveness of sandwich construction, it is thus essential to better understand the local strength characteristic of sandwich panel/beam members.

The main objective of this study is to prepare a galvanized iron-glass fiber sandwich panel and test for the tensile test properties of the sandwich panel using universal testing machine.

\subsection{Galvanized Iron}

\section{Material Used}

Galvanization, or galvanization, (or galvanizing as it is most commonly called in that industry), is the process of applying a protective zinc coating to steel or iron, to prevent rusting. The most common method is hot-dip galvanizing, in which parts are submerged in a bath of molten zinc. It forms a coating of corrosion- 
resistant zinc which prevents corrosive substances from reaching the more delicate part of the metal. The zinc serves as a sacrificial anode so that even if the coating is scratched, the exposed steel will still be protected by the remaining zinc. The zinc protects its base metal by corroding before iron, for better results application of chromates over zinc is also seen as an industrial trend.

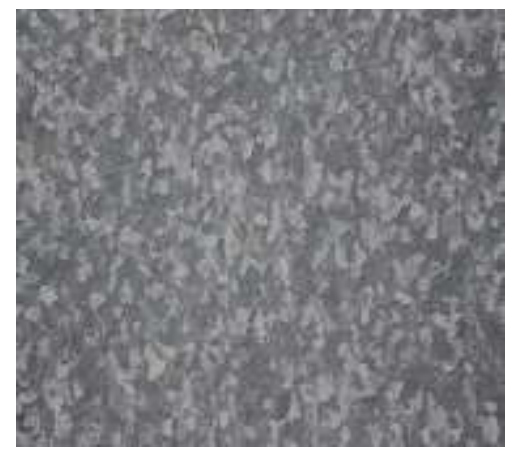

\subsection{Glass Fiber}

Fiberglass (or fiberglass) is a type of fiber reinforced plastic where the reinforcement fiber is specifically glass fiber. The glass fiber may be randomly arranged, flattened into a sheet (called a chopped strand mat), or woven into a fabric. The plastic matrix may be a thermosetting plastic - most often epoxy, polyester resin - or vinyl ester, or thermoplastic. The glass fibers are made of various types of glass depending upon the fiberglass use. These glasses all contain silica or silicate, with varying amounts of oxides of calcium, magnesium, and sometimes boron. To be used in fiberglass, glass fibers have to be made with very low levels of defects. Fiber glass is a strong lightweight material and is used for many products. Although it is not as strong and stiff as composites based on carbon fiber, it is less brittle, and its raw materials are much cheaper. Applications of fiberglass include aircraft, boats, automobiles, bath tubs and enclosures, swimming pools, hot tubs, septic tanks, water tanks, roofing, pipes, cladding, casts, surfboards, and external door skins.

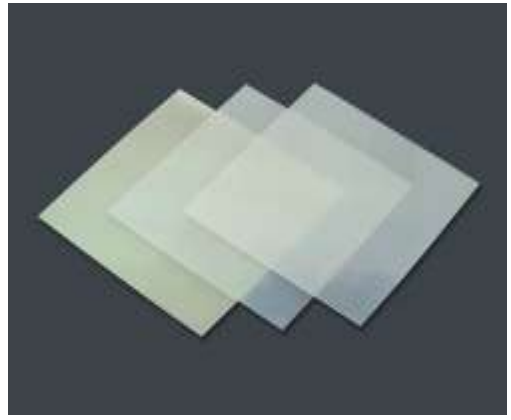

\subsection{Copped Strand Mat}

Chopped strand mat or CSM is a form of reinforcement used in fiberglass. It consists of glass fibers laid randomly across each other and held together by a binder. It is typically processed using the hand lay-up technique, where sheets of material are placed in a mould and brushed with resin. Because the binder dissolves in resin, the material easily conforms to different shapes when wetted out. After the resin cures, the hardened product can be taken from the mould and finished. Using chopped strand mat gives a fiberglass with isotropic in-plane material properties

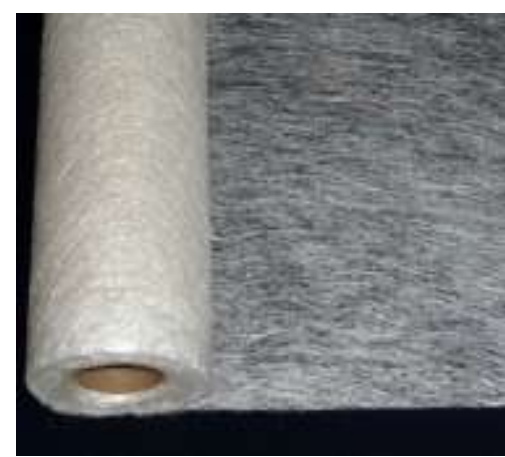




\subsection{Resin and Hardener}

In polymer chemistry and materials science, resin is a "solid or highly viscous substance," which is typically convertible into polymers. Such viscous substances can be plant-derived or synthetic in origin. They are often mixtures of organic compounds. The resin produced by most plants is composed mainly of terpenes and derivatives. The most common terpenes in resin are the bicyclic, delta- 3 carene, and sabinene, themonocyclicterpenes limonene and terpinolene, andtricyclic sesquiterpenes, longifolene, caryophyllene and del ta-cadinene. Some resins also contain a high proportion of resin acids. The individual components of resin can be separated by fractional distillation. Rosins on the other hand are less volatile and consist, inter alia, of diterpenes.

Hardener is the one that hardens; especially a substance added (as to a paint or varnish) to harden the film. Both resin and hardener are mixed together and the mixed part is used to join the two surfaces

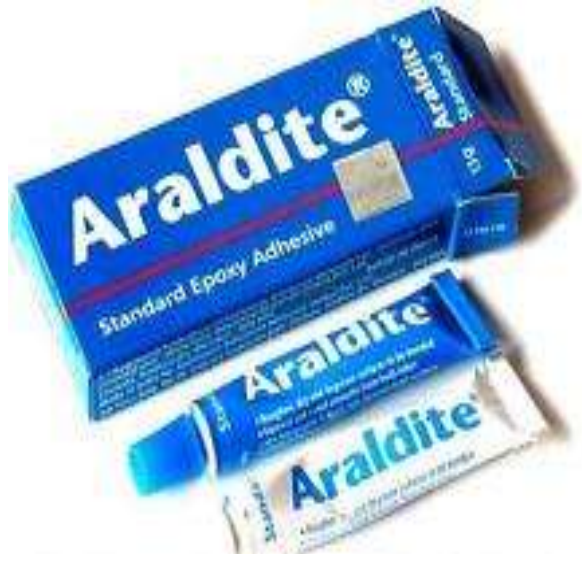

\section{Experimental Setup}

\subsection{Preparation of composite specimen}

The surface of the Galvanized iron sheet and the inner surface of the mould cavity were coated with wax. The Galvanized iron sheet was placed inside the mould with the roughened surface facing up. A coating of the resin-hardener mixture was applied over the Galvanized iron surface followed by placing the CSM over the above coating. Two layers of unidirectional (UD) fibers wetted with resin hardener mixture were then placed over the CSM. A CSM layer was again placed over which the outer Galvanized iron sheet was placed. The mould cavity was closed by a wax coated acrylic sheet. Weights were placed over the sheet in such a way that uniform pressure was obtained. The set up was left for curing for 6 hours at room temperature.

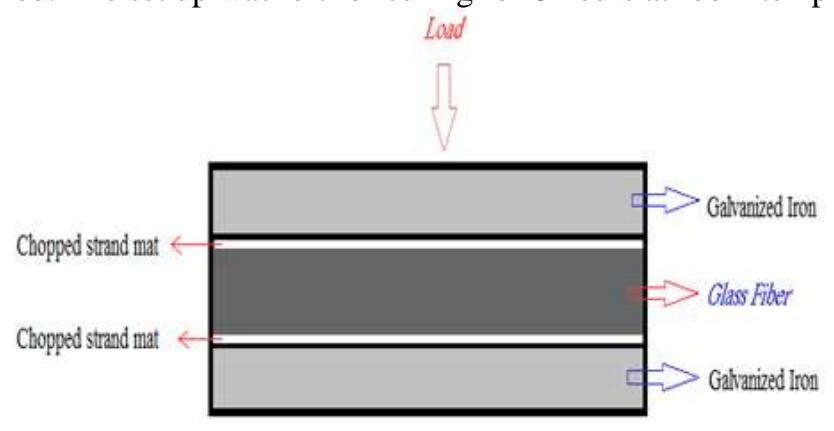

\subsection{Tensile properties}

\section{Results and Discussion}

The hybrid composite material fabricated is cut into required dimension using a saw cutter and the edges finished by using emery paper for mechanical testing. The tensile test specimen is prepared according to the ASTM D638 standard. The dimensions, gauge length and cross-head speeds are chosen according to the ASTM D638 standard. A tensile test involves mounting the specimen in a machine and subjecting it to the tension. The testing process involves placing the test specimen in the testing machine and applying tension to it until it fractures. The tensile force is recorded as a function of the increase in gauge length. During the application of tension, the elongation of the gauge section is recorded against the applied force. Below given details are the length, width and thickness of the specimen.

Below figure shows the tensile testing of the specimen conducted on universal testing machine (UTM). Photo has been taken after testing specimen breaks into two parts. Length $=250 \mathrm{~mm}$, width $=20.84 \mathrm{~mm}$, thick $=3.78 \mathrm{~mm}$ 


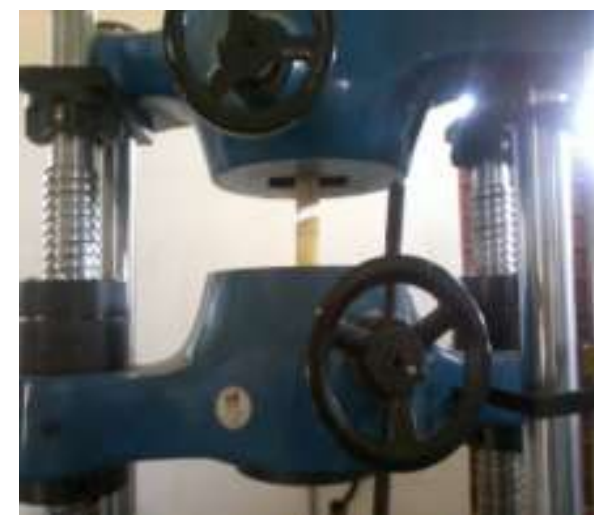

Specimen during testing Below figure shows the specimen after tensile testing. It shows that it has been broke into two parts.

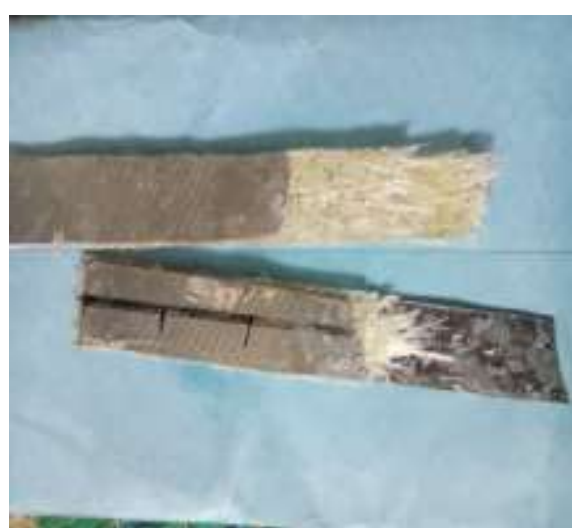

Tested Specimen The sample graph of flexural strength observed for the Galvanized iron-glass fiber composites. The result indicated that the Maximum applied load up to around $200 \mathrm{KN}$, Maximum elongation $200 \mathrm{~mm}$

Specimen cross section area Final gauge length

$78.73 \mathrm{~mm}^{2}$ and

$64.84 \mathrm{~mm}$

\section{Output Data}

Load at yield

Yield stress

Load at peak

Tensile strength

$\%$ Elongation
$5.87 \mathrm{~mm}$

$74.516 \mathrm{~N} / \mathrm{mm}^{2}$,

$7.170 \mathrm{KN}$,

$91.018 \mathrm{~N} / \mathrm{mm}^{2}$ and

$29.68 \%$.

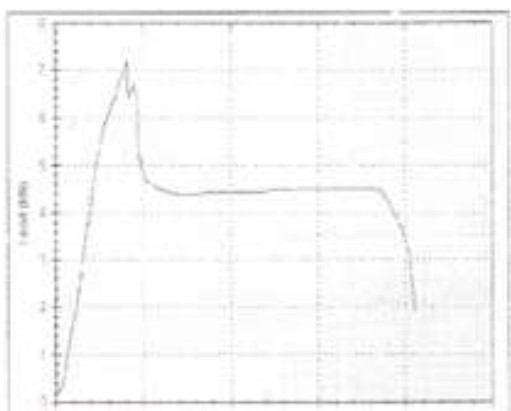

Tensile testing graph Below figure shows the certificate of testing taken from Raghavendra Spectro Metallurgical Laboratory. Certificate shows the complete details about specimen before testing and after testing. 


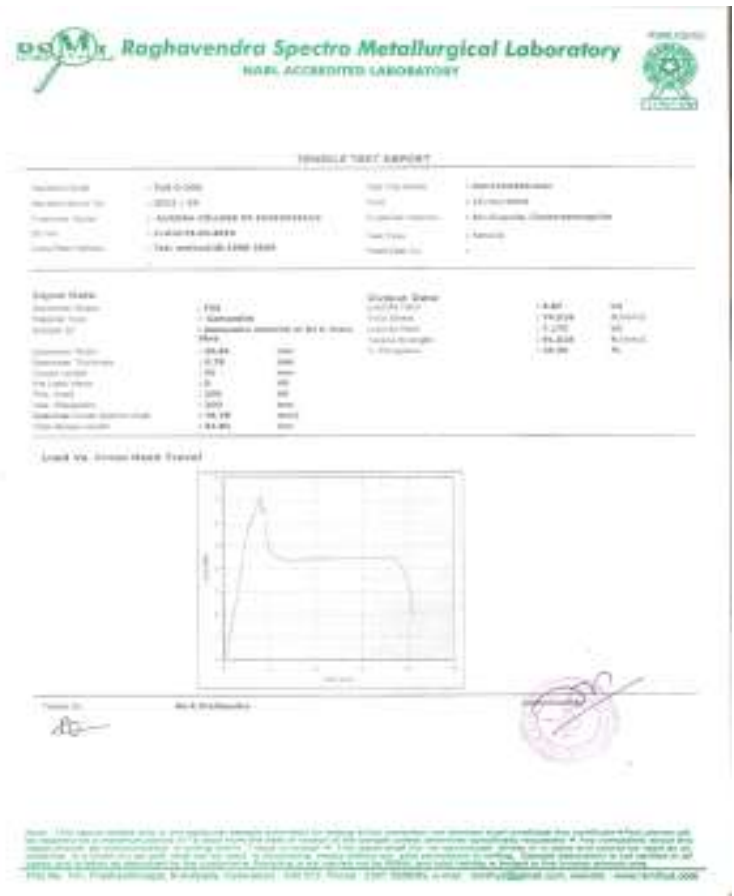

\section{CONCLUSION}

Tensile test is conducted on the galvanized iron alloy glass fiber sandwich panel and it is observed that galvanized iron alloy glass fiber sandwich panel has more strength to weight ratio compared to uniform galvanized iron. From tensile test on the specimen it was observed that the start of plastic deformation could be delayed, resulting in increase of ultimate strength. From tensile test of composite material, tensile strength capacity of sandwich panel is more compare to monolithic materials. Hence sandwich panel composite material is acceptable in Automobile, Aerospace, and Marine engineering. The experimental tests have demonstrated that the light weight Galvanized iron panels have good properties of energy dissipation and the amount of energy absorption under tensile test can be highly improved by reinforcing them by means of Glass fiber sheets, which can be designed according to the application of the sandwich. Tensile analysis is done on galvanized iron alloy glass fiber sandwich panel and there will be scope for study on square, TPS (flat walls) and TPS (corrugated walls) panels. In addition to the importance of reinforcement and matrix in polymer composites, the tensile strength between the sheets is key issue for overall metal fiber laminate performance. An adequate surface treatment of the metallic layer is required to assure a good mechanical and adhesive bond between the sheets.

\section{Reference}

[1]. Gurustal Somnath Swamy.et al. Bending moment of galvanized iron glass fiber sandwich panel, Int. Journal of Engineering Research and Applications, ISSN: 2248-9622, Vol. 6, Issue 5, (Part - 5) May 2016, pp.47-51.

[2]. K.Alagarraja.et al. Fabrication and testing of fiber reinforced Polymer composites material, IOSR Journal of Mechanical and Civil Engineering (IOSR-JMCE) e- ISSN: 2278-1684, p-ISSN: 2320-334X PP 2734 www.iosrjournals.org.

[3]. Gurustal Somnath Swamy.et al. Bending Moment of Aluminium Alloy Glass Fiber Sandwich Panel, International Journal of Innovative Research in Science, Engineering and Technology, ISSN (Online): 2319-8753 ISSN (Print): 2347-6710, (An ISO 3297: 2007 Certified Organization) Vol. 5, Issue 5, May 2016.

[4]. Isaac M. Daniel, Jandro. L, Abot. J. (2000). Fabrication, testing and analysis of composite sandwich beams

[5]. Herranen. H, Pabut. O, Eerme. M, Majak. J, Pohlak. M, Kers. J \& Aruniit. A (2012). Design and testing of sandwich structures with different core materials. Materials Science.

[6]. Kaveh Kabir, Tania Vodenitcharova, Mark Hoffman, "Response of galvanized iron foamcored sandwich panels to bending load"Elsevier, Composites: Part B 64 (2014).

[7]. Fakhrurrazi b ab karim have studied on experimental and finite element evaluation of bending for Galvanized iron, Jan 2013, universiti malaysia pahang.

[8]. V. Crupi, G. Epasto, E. Guglielmino, "Comparison of galvanized iron sandwiches for lightweight ship structures: Honeycomb vs. foam”, Elsevier, Marine Structures 30 (2013). 